OCCASIONAL REVIEW

\title{
Respiratory medical societies and the threat of bioterrorism
}

\author{
T G O'Riordan, G C Smaldone
}

Thorax 2004;59:265-267. doi: 10.1136/thorax.2003.015321

Respiratory medical societies throughout the world have an important role in helping governments to develop public policy to counter the threat of bioterrorism.

$\ldots \ldots \ldots \ldots \ldots \ldots \ldots$

$R$ ecent events have radically, and perhaps permanently, altered our perception of the threat posed by terrorists to civil society. The world Trade Center bombings in New York on 11 September 2001 showed that terrorists have both the technical capacity and the willingness to inflict mass civilian casualties in western democracies. In addition, in October 2001 the United States postal service became the focus of an anthrax outbreak. It affected not only the targets of the attacks-which were political and media institutions-but, in addition, caused inadvertent deaths and illness among postal employees and members of the general public. ${ }^{1-4}$ This latter incident emphasised the dangers posed to large populations and complex organisations of very small quantities of biotoxic agents, but also exposed the public health services to close and critical scrutiny. These incidents have combined to reshape the policies of western democracies to combat threats against civilian populations and industrial infrastructure, including a significant increase in the budgeting of resources to combat bioterrorism

The United States Centers for Disease Control (CDC) has classified six agents as category A threats, based upon the dangers posed by the agents as well as the perceived feasibility of weaponisation. ${ }^{5}$ The agents are Bacillus anthracis (anthrax), Variola major (smallpox), Yersinia pestis (plague), Francisella tularensis (tularaemia), viral haemorrhagic agents, and Clostridium botulinum toxin. Category B and C agents ${ }^{6}$ are seen as posing a less imminent threat but include other agents of interest to respiratory physicians such as Coxiella burnetti (Q fever), Hantavirus, and multidrug resistant Mycobacterium tuberculosis. The principal route of delivery of bioterrorist agents is by the inhalation of aerosols. Furthermore, many of the manifestations of these agents can appear as respiratory illnesses or in the setting of critical care medicine. Respiratory physicians and others associated with respiratory medical societies are at the unique intersection of disciplines whose involvement is essential to ensure an adequate response to this threat, including public health personnel, occupational medical specialists, aerosol physiologists, and microbiologists. The American Thoracic Society (ATS) recently formed a new section devoted to bioterrorism and other societies have either formed working groups or are considering doing so. We believe that national and regional respiratory societies and colleges such as the British Thoracic Society (BTS), the European Respiratory Society (ERS), the American College of Chest Physicians (ACCP), the Society for Critical Care Medicine (SCCM), and the International Society for Aerosols in Medicine (ISAM) - to name but a few-can provide an important forum for the exchange of ideas and the development of public policy. The interests of respiratory medical societies can be approached under three main headings:

- surveillance;

- preparation for response;

- research.

\section{SURVEILLANCE}

\section{Education and case recognition}

Respiratory physicians are likely to be among the first clinicians to encounter the sentinel cases of a bioterrorist outbreak and, as a result, the respiratory medical societies have a responsibility to educate their membership in the recognition of bioterrorism related conditions which are likely to present in the setting of an acute pneumonic illness or in critical care (anthrax as septic shock or an abnormal chest $x$ ray, plague and tularaemia as pneumonia, botulism as ventilatory failure). ${ }^{5}$

\section{Database design}

Respiratory medical societies should have input into the design of the elaborate database systems that have been proposed as surveillance ${ }^{7}$ because many of the conditions likely to be documented are respiratory and critical care illnesses. In addition to commenting on the epidemiological and administrative aspects of such databases, they should fulfil their role as patient advocates, ensuring than databases do not infringe on the right of patients to privacy.

\section{Developing rationale for electronic detectors and understanding behaviour of biologically important aerosols}

Many proposals have been put forward for the placement of electronic detectors to provide early warning of bioaerosol assault. ${ }^{8}$ The successful implementation of such systems requires multidisciplinary input from specialists in engineering, microbiology, and aerosol toxicology. Respiratory societies should work to bring these disciplines together.

The anthrax outbreak of 2001 brought the arcane subject of aerosol delivery and lung deposition into the popular press. The manufacturers of the strain of anthrax involved in these attacks demonstrated a significant degree of 
sophistication in the production of these spores. Not only were the particles small enough to be aerosolised and remain in the ambient air, they also may have been modified to reduce the electrostatic charges that result in the clumping of naturally occurring anthrax spores, thus increasing the ability of the modified spores to remain airborne. Furthermore, some of our postal technology (compressive letter sorting machines and air jets used to clean machinery) may have inadvertently facilitated the spread of this aerosol. ${ }^{3}$ The unpredictability of dose response of biologically active aerosols was further shown by the fact that two members of the public died of inhalation anthrax, almost certainly as a result of contaminated mail. These problems illustrate a fundamental lack of knowledge about the behaviour of specific aerosols under specific circumstances and underline the need for greater investment in models that predict how these agents are delivered and deposited as well as how they cause disease.

\section{Supporting public health investment}

Many respiratory medical societies were founded is response to tuberculosis and have a strong tradition of supporting clinically, politically, and academically the public health services, a tradition on which we should continue to build. A well organised public health service is essential for biosecurity. The skills needed to recognise new patterns of diseases, identify sentinel cases, trace contacts, provide specific advice on isolation measures, and liaise with reference microbiological laboratories are integral to public health training and practice. Recent events such as the detection of West Nile virus and monkey pox, the SARS (severe acute respiratory syndrome) epidemic, and the anthrax outbreak have raised the profile of public health in the US, which had tended to be treated by political leaders as a marginalised "welfare" activity rather than as part of national security. ${ }^{9}$ Increased funding and status for public health, even if motivated by national security concerns, is nevertheless likely to benefit many of the more vulnerable members of society as well as providing protection from new naturally occurring infections. The devastating economic consequences predicted by the Johns Hopkins Civilian Biodefense Center's "dark winter" scenario of a smallpox outbreak makes the case that public health spending is not only a social service but also a prudent insurance against economic disaster. ${ }^{10}$

\section{PREPARATION FOR RESPONSE}

\section{Design of emergency stockpiles of medical supplies}

Since 1999 the US government has made significant progress in developing a system of emergency response stockpiles of essential medications and vaccines. ${ }^{311}$ Exact details of the contents and location have not been released for security reasons, but the stockpiles are strategically located around the country and can be moved rapidly to an outbreak zone. The anthrax outbreak was an opportunity to test the system, and it functioned well. Other governments are well advised to follow this example, and respiratory societies have a role in advising on the composition and location of these pharmaceutical reserves.

The development of a potentially dangerous "run" on ciprofloxacin, the only approved agent in the US against anthrax at the time of the outbreak, emphasised the importance of having more than one antibiotic approved to treat a specific condition. Several antibiotics have since been approved as suitable for the treatment of anthrax, making a panic run less likely if there is a new attack.

\section{Health system surge capacity}

The SARS epidemic has drawn attention to the need for "surge capacity" in the health service. ${ }^{12}$ A major bioterrorism attack would greatly increase the need for hospital services for complex, critically ill patients. Respiratory societies should have input into how the national and regional health systems would respond to an increase in the need for intensive care beds and ventilators, especially as many of these systems are at maximum capacity already and in most European countries the percentage of hospital beds designated for critical care purposes tends to be lower than in North America.

\section{Ameliorating panic and social disruption}

In addition to the physical dangers of a bioterrorist attack, one must consider the psychological dangers. Within minutes of the announcement of the diagnosis of anthrax in Florida, hoax calls and powder filled envelopes began to appear all over the US. The sight of emergency response workers in protective clothing arriving at offices and removing powder which they did not have the facilities to analyse in a timely manner created a great deal of public disquiet. Many of these first response workers had never received any training in the area of bioterrorism. There are two potential ways in which our Societies could contribute to controlling such panic. The first is by providing web access to peer reviewed educational materials either to the general public or to emergency services, in the recognition and management of potential exposures. The second is by promoting research into the development of techniques that can provide rapid identification and diagnosis of suspected powders and patient samples, respectively.

One promising technique being developed in veterinary medicine is real time remote access PCR technology. Using these techniques a veterinarian visiting an isolated farm can now confirm a suspected case of swine flu or foot and mouth disease within an hour compared with a 1 week delay with traditional diagnostic procedures. ${ }^{13}{ }^{14}$ If such techniques were developed for bioterrorist agents, not only could outbreaks be confined more quickly but the panic associated with false positives and hoaxes could be greatly curtailed.

\section{Need to distinguish between potential and imminent threats}

The recent controversy over smallpox vaccination in the $U^{15}$ is likely to be only the first example of such a controversy and respiratory medical societies will be expected to contribute to these debates. Although no spontaneous case of smallpox has been recorded in a quarter of a century, terrorist groups and their state sponsors may have access to a virus that has killed over 100 million people. ${ }^{5}$ The mortality from Variola major in the unvaccinated is estimated to be $20-40 \%$, but there is a small but significant risk of complications from vaccination and there is a narrow window for post exposure vaccination of approximately 1 week. ${ }^{5}$ Some preparative measures were without controversy, such as the plan to increase the number of vaccine doses from 15 to 200 million as well as the production of additional doses of immune globulin to treat vaccinia. Although vaccination of military personnel before an expected war with Iraq was accomplished, plans to vaccinate a core group of first responder civilian healthcare workers were placed on hold after the death of two volunteers apparently from vaccine related complications. The distinction between a potential threat and an imminent threat can be difficult to determine and is quite controversial. Respiratory societies as non-government institutions with credibility and technical expertise will be expected to participate in threat evaluation and risk-benefit analysis. 


\section{SUPPORTING RESEARCH TO COMBAT BIOTERRORISM}

The US government has quadrupled its research budget devoted to bioterrorism over the past 3 years and other governments are also likely to increase resources. Respiratory medical societies have a responsibility to use their considerable technical expertise in aerosol research, microbiology, critical care, and therapeutics to ensure that this money is spent wisely. Among the areas that would benefit from investment in research are: models that predict transmission of bioaerosols, rapid diagnostic tests, more effective and safer vaccines, antibiotic evaluation, and novel antitoxins. It is inevitable that such research will have benefits beyond bioterrorism. For example, investment in vaccine development is likely to confer serendipitous benefits on the world's poorest countries.

Much of the focus of research being funded by the US National Institute for Allergy and Infectious Diseases (NIAID) is likely to be on specific pathogens. Because of the diverse backgrounds and interests of their membership, respiratory societies could promote a more integrative approach to bioterrorism research with emphasis on activities that require multidisciplinary approaches-for example, aerosol deposition in the lung, critical care/acute respiratory failure, occupational exposures, and defence against weapons containing more than one agent.

A former Soviet researcher in bioweapons, Dr Ken Alibek, has described the sophisticated and secret programmes developed by the Soviet Union that included genetic manipulation of microorganisms not only to confer resistance to antibiotics and vaccines but also the incorporation of human genes in an effort to stimulate autoimmune reactions. ${ }^{16}$ As a result of this and other information, our research efforts must try to prepare for new threats. The failure of models of anthrax transmission based on data from naturally occurring $B$ anthracis to predict the outcome of the anthrax outbreak in October 2001 should serve as a warning against complacency.

\section{Authors' affiliations}

T G O'Riordan, G C Smaldone, Division of Pulmonary/Critical Care Medicine, Stony Brook University, New York

\section{REFERENCES}

1 Bush LM, Abrams BH, Beall A, et al. Index case of fatal inhalational anthrax due to bioterrorism in the United States. N Engl J Med 2001;345:1607-10.

2 Hughes JM, Gerberding JL. Anthrax bioterrorism: lessons learned and future directions. Emerg Infect Dis 2002;8:1013-4

3 Perkins BA, Popovic T, Yeskey K. Public health in the time of bioterrorism. Emerg Infect Dis 2002;8:1015-7.

4 Jones J, Terndrup TE, Franz DR, et al. Future challenges in preparing for and responding to bioterrorism events. Emerg Med Clin North Am 2002;20:501-24.

5 Darling RG, Catlett CL, Huebner KD, et al. Threats in bioterrorism. I: CDC category A agents. Emerg Med Clin North Am 2002;20:273-309.

6 Moran GJ. Threats In Bioterrorism II: CDC Category B and C agents. Emerg Med Clin North Am 2002;20:311-36.

7 Pavlin JA, Mostashari F, Kortepeter MG, et al. Innovative surveillance methods for rapid detection of disease outbreaks and bioterrorism: results of an interagency workshop on health indicator surveillance. Am J Public Health 2003;9:1230-5

8 Kline CR Jr. High-speed advanced sensors for bioterror weapons. What we have done, what more needs to be done now, and what needs to be done in the future. IEEE Engineering Medicine \& Biology Magazine 2002;21:43-7.

9 Garrett L. Betrayal of trust: the collapse of global public health. New York: Hyperion, 2000.

10 Johns Hopkins Center for Civilian Biodefense. Dark winter. www.hopkinsbiodefense.org/darkwinter.html.

11 Esbitt D. The strategic national stockpile: roles and responsibilities of health care professionals for receiving the stockpile assets. Disaster Manag Response 2003; 1:68-70.

12 Karwa M, Bronzert P, Kvetan V. Bioterrorism and critical care. Crit Care Clin 2003; 19:279-313.

13 Callahan JD, Brown F, Osorio FA, et al. Use of a portable real-time reverse transcriptase-polymerase chain reaction assay for rapid detection of foot-andmouth disease virus. J Am Vet Med Assoc 2002;220:1636-42.

14 Risatti GR, Callahan JD, Nelson WM, et al. Rapid detection of classical swine fever virus by a portable real-time reverse transcriptase PCR assay. J Clin Microbiol 2003;41:500-5.

15 Baltimore RS, McMillan JA. Smallpox and the smallpox vaccine controversy. Pediatr Infect Dis J 2002;21:789-90.

16 Alibek K, Handelsman S. Biohazard. New York: Dell Publishing, 1999. 